\title{
Gender Differences in Realization Patterns of Disagreement in Chinese
}

\author{
Yang Yan \\ Faculty of Foreign Languages and Cultures of Kunming University of Science and Technology, Kunming, China \\ yangyanhch@163.com
}

\begin{abstract}
Studies on gender differences in realization patterns of disagreement in Chinese context, by so far, have been found insufficient. Disagreement is a commonly-occurred speech act in everyday human interactions and by its very nature is a facethreatening act that harms the solidarity between speaker and addressee and demands the employment of pragmatic strategies. The present study is an empirical research which aims to explore gender differences in disagreement realization strategies in Chinese with DCT and interview being the instrument of data collection. Meanwhile, an attempt was made to explain gender differences within the theoretical framework of Brown and Levinson' politeness theory and Gu Yueguo's Chinese politeness maxims. In addition, the cause of gender differences in language use was traced from psychological and socio-cultural point of views.

Index Terms - speech act, disagreement, gender difference, realization patterns
\end{abstract}

\section{Introduction}

The concept of gender is first put forward by Simone de Beauvoir, a French writer and feminist. Gender here concerns the psychological, social and cultural differences that have been established between men and women. As gender differences are a fundamental fact of human life, so it is not surprising to find these differences reflected in language. Since the early 1970s, research on language and gender has been receiving more attention from linguists, pioneered by Robin Lakoff [1].Traditional empirical research in sociolinguistics placed emphasis on gender differences in phonological, morphological and lexical levels while the recent study of language and gender has increasingly become the study of discourse and gender both from sociolinguistic and pragmatic perspectives. The interdisciplinary investigation of discourselevel phenomena, always a robust area of language and gender scholarship, has become the central approach of the field. According to the Speech Act Theory proposed by Searle, the term "speech act" has been defined as a minimal unit of linguistic communication. [2].The research on speech acts is an important aspect of the study of human's communicative competence and a significant facet of the study of language use. Thus research of this kind is to contribute to the understanding of human's linguistic performance and corresponding strategic use. For this purpose, gender differences in the use of certain speech act have aroused the interest of many scholars. Many researchers home and abroad carried out their research on gender differences in the speech act of complimenting [3]; apologizing; requesting [4]; and refusal [5]. There are a few studies on gender and realization patterns of disagreement in English context. Relevant research on the Chinese language is still in its infancy. The inadequacy of the investigation of gender and disagreement gives stimulus to the study. The classification of the disagreement strategies in the present study is based on the taxonomy established by Rees-Miller who categorizes disagreement strategies into three broad types: mitigated disagreement, disagreement not softened or strengthened and aggravated disagreement.[6] Yet in the pilot study of the instrument of this thesis, we found that the frequency of disagreement not softened or strengthened is almost none in our data of this study, it is excluded in the present study. Consequently, disagreement strategies in the present study are classified into two broad types: mitigated strategies and aggravated strategies. In terms of semantic formulae of mitigated and aggravated strategies, there is no available taxonomy which is appropriate for analyzing the data in the present study. So the author absorbs the results from the following research: Muntigl \& Turnbull [7], Rees-Miller, [6], Wang [8], Liu [9], Liang [10] and revisions are made for the fulfillment of the purpose of the study. So the semantic formulae of mitigated strategies in the present study are further divided into Hedges, Questions; Positive Remarks and Expression of Gratitude plus Avoiding. On the other hand, the semantic formulae of the aggravated strategies are classified into Judgmental Vocabulary, Direct Disagreement and Rhetorical Questions.

The present study employed DCT and interview as the datagathering method and 200 students including 100 male students and 100 female students as the random sample from Southwest Jiaotong University. In terms of the nature of pragmatic theories, researchers creating measures in pragmatic studies must provide situations of language use [7], so ten situations are embedded in the DCT to elicit the disagreement responses.

The present study attempts to answer the following questions:

A. What is the overall tendency of disagreement strategies use between males and females?

B. Do the realization patterns of disagreement differ between males and females?

C. What are the causes of gender differences in realization patterns of disagreement in Chinese?

2. Gender Differences in the Use of Disagreement Strategies

The obtained occurrences of each type of strategy used by the two groups are presented in Table 1.From it, we can 
observe that, on average, both males and females use more mitigated strategies when disagree with others. The proportion of mitigated strategies used by the two groups in overall situations amounts to $85 \%$ of the total number of strategies. Males was observed to utilize 3.55 times as many as mitigated strategies $(78 \%)$ versus aggravated strategies, whereas females was observed to utilize 11.39 times as many as mitigated strategies $(92 \%)$ versus aggravated strategies. Although both males and females use more mitigated strategies than aggravated strategies, the greater preference for mitigated strategies on the part of females should be noticed.

T-test was employed to examine the statistically significant differences across the two types of strategies for each group. The t-test analysis proves that there are statistically significant difference in the use of both aggravated strategies and mitigated strategies $(\mathrm{t}=6.20, \mathrm{P}=0.05)$ between males and females.

TABLE 1 Distribution of Two Types of Strategies

\begin{tabular}{|l|l|l|}
\hline \multicolumn{2}{|l|}{$\begin{array}{l}\text { Total Occurrences of Mitigated and Aggravated Strategies in } \\
\text { Overall Situations }\end{array}$} \\
\hline \multirow{2}{*}{ Types } & Groups \\
\cline { 2 - 3 } & M & F \\
\hline Mitigated strategies & 390 & 432 \\
\hline Aggravated strategies & 110 & 38 \\
\hline Total No. & 500 & 470 \\
\hline
\end{tabular}

(Note: $\mathrm{M}$ refers to male; $\mathrm{F}$ refers to female.)

\section{A. Mitigated Strategies Uses between Males and Females}

According to Brown and Levinson, disagreement is a face-threatening speech act [11]. Consequently, the mitigated strategies are preferred when expressing disagreement in order to enhance the solidarity and harmonious relationship between interlocutors. By adopting mitigated strategies when showing his/her opposite position, the speaker is attentive to the addressee's face needs and minimizes face threat to the addressee.

As Table 2 suggests, mitigated strategies utilized in the present study include: hedges, question; positive remarks, and expression of gratitude plus avoiding. We can find: the realization patterns of mitigated strategies by males are following this trend: Expression of Gratitude plus Avoiding>Positive remarks, Hedges, Question respectively. Females' realization patterns of mitigated strategies are: expression of gratitude plus avoiding>hedges, positive remarks, questions respectively.

TABLE 2 Distribution of mitigated strategies in overall situations

\begin{tabular}{|l|l|l|}
\hline Total Occurrences of Every Mitigated Strategies in Overall Situations \\
\hline \multirow{2}{*}{ Types } & Groups \\
\cline { 2 - 3 } & M & F \\
\hline Hedges & 81 & 86 \\
\hline Question & 76 & 71 \\
\hline Positive Remarks & 84 & 72 \\
\hline Expression of Gratitude plus Avoiding & 149 & 203 \\
\hline Total No. & 390 & 432 \\
\hline
\end{tabular}

\section{B. Aggravated Strategies Uses between Males and Females}

TABLE 3 Distribution of aggravated strategies in overall situations

\begin{tabular}{|l|l|l|}
\hline Total Occurrences of Every Aggravated Strategies in Overall Situations \\
\hline \multirow{2}{*}{ Types } & Groups \\
\cline { 2 - 3 } & M & F \\
\hline Judgmental Vocabulary & 30 & 4 \\
\hline Direct Disagreement & 46 & 8 \\
\hline Rhetorical Question & 34 & 26 \\
\hline Total No. & 110 & 38 \\
\hline
\end{tabular}

As Lobov and Franshel argues that within conversation, participants may select to perform actions in either mitigated or modulated ways, or alternatively in aggravated or unmodulated ways [10]. As far as the speech act of disagreement is concerned, the speaker can either adopt various mitigated strategies to postpone the position of opposition with respect to the utterance articulated by prior speaker and soften his/her disagreement or immediately adopt aggravated strategies to put forward counter opinion in unmitigated fashion and aggravated his/her disagreement.

The aggravated strategies involved in the present study are presented in Table 3. They are: judgmental vocabulary; direct disagreement; rhetorical question. It can be observed that males use more direct disagreement than rhetorical question, judgmental vocabulary respectively when showing their disagreement towards others, and females use more rhetorical question than direct disagreement, judgmental vocabulary.

\section{Analysis on the Cause of Gender Differences}

\section{A. The psychological perspective}

The psychological differences between males and females have long been studied by many psychologists. According to the research of Atwater, in Childhood, boys learn to think abstractly and they have a good sense of space, direction and number calculation, while girls learn to think concretely and they are talented for language, the perception of emotions and the differentiation of color [12].

These psychological differences inevitably results in differences in language use between males and females. As mentioned before, females have a good sense of language, so they have superiority over boys in the acquisition of speech. On measures such as the onset of babbling, the first word, and number of words used at 18 months, girls tend to do better than boys. This contrast between girls and boys seems have been exaggerated in the past, although it has been suggested that differences between male and female children might be diminishing as a reflection of less polarized gender roles and less sexist modes of child cared in contemporary societies. However, Maccoby and Jacklin's [13] authoritative survey of all extant research in the area concluded that the generalization still holds good. For pre-school children, the research findings indicated that where a gender difference is found, it is nearly always girls who are ahead. So females are often observed to use standard speech. 
Because of the psychological characteristics, females are relation-oriented and they are dependent, passive; cooperative; diffident; timid and so on and so forth; while males are activity oriented, active competitive; ambitious and confident. These psychological characteristics do affect the language use between males and females. Robin Lakoff [1] listed ten features of females' language: hedges (sort of, kind of, I guess), polite forms (would you please..., I'd really appreciate it if...); tag questions; speaking in italics (emphatic so and very); empty adjectives (divine, charming, sweet); hypercorrect grammar and pronunciation; lack of a sense of humor (poor at telling jokes); direct quotation; special vocabulary (specialized color terms) and question intonation in declarative contexts. In this case, it is often females that are more likely to use polite speech rather than males in conversation. On the contrary, males tend to be confrontational and aggressive in communication with others, paying more attention to power and status than females, just as a psychologist once said "A man might ask a woman, "will you please go to the store?' where a woman might say, 'Gee, I really need a few things from the store, but I'm so tired'". The women's style is called "covert", a term suggesting negative qualities like being "polite" and "underhanded". The reason offered for this is women's psychological characteristics which are obviously different from that of males.

\section{B. Social and cultural perspectives}

Due to the differential distribution of power in the society, women are viewed and treated as unequal to men. The norms of society had literally been established by men. The division of labor between women and men was seen to include a division of languages practices, one belonging to the powerful and the other belonging to women. Language differences were identified as part of a structure of unequal access and influence.

In general, women are in powerless position in society compared with men. Many women therefore typically use powerless language, according to O'Barr and Atkins [13], but this is the result of their position in society rather than of their gender. Zimmerman and West [14] analyzed doctor-patient interaction in a local clinic and discovered, among other things, that doctors regularly interrupt their patients, except when the doctor is females and the patient is white and males. This finding suggests that even when a woman is in o position of power, it is her gender, not her status, which enables us to predict who interrupts whom. The finding that gender overrides status is confirmed by Woods who made recordings of three-party conversations between work colleagues of differing occupational status. In some cases, a male speaker held the "boss" position. While occupational status did have some influence on floor-holding, it was men who dominated, whether they were boss or subordinate. Being the boss doesn't lead to women holding the floor more than man.

It has been suggested that those who are powerless must be polite. So in communities where women are powerless members of a subordinate group, they are likely to be more linguistically polite than the men who are in control. Women pursue a style of interaction based on solidarity and support, while men pursue a style based on power. Kalcik [15] studied personal narrative in all-women groups and argued that the prime pattern of interaction in such groups is cooperative rather than competitive, and this is confirmed by Aries's [13] work on mixed and single- sex groups. Aries analyzed the interaction patterns of six experimental groups: two-all female, two all-male, and two mixed. The all-male-groups were concerned to establish where each member stood in relation to other members and in these groups a hierarchy emerged with some members holding dominant positions and others more submissive positions. The two women's groups, on the other hand, were more flexible: active speakers were concerned to draw out more reticent speakers and the women developed ways to express affection and interpersonal concern. An emphasis on in-group solidarity is a feature of oppressed groups. Subordinate groups tend to stress the values and attitudes whish distinguish them from those who dominate them. So the Dominance Model gives us the possible explanation for why women are more polite than men in general.

Some researchers such as Daniel Maltz ,Ruth Borker and Deborah Tannen [16], hypothesized that women and men used specific and distinct verbal strategies and communicative styles which were developed in same-sex childhood peer groups and they advocated that gender differences in conversational style results from differences in the socialization of boys and girls. Researchers following the Difference Approach see the linguistic difference between males and females as the result of the different subcultures where males and females are socialized.

Boys and girls have been taught to learn genderappropriate language since their childhood. In the family, parents encouraged boys to be brave, independent and strong, while girls are expected to be tender, obedient and considerate. Edelsky [17] study of the language of parents when they play with their children revealed that both fathers and mothers use more directives with their sons than with their daughters. Goodwin's work on the street play of Black children in Philadelphia established that the linguistic forms used by the children reflected the social organization of their social groups: the non-hierarchical nature of the girls' group resulted in the use of co-operative rather than competitive forms. Goodwin noticed that boys used different sorts of directive from girls. The boys in her study preferred directives explicitly and aggregately to establish status differences between participants. The girls, by contrast, typically used more mitigated directives.

It is now widely accepted that the peer-group is of vital importance in a child's sociolinguistic development. Girls and boys tend to play in same-sex groups. Streak describes the behavior of the children he observed in primary school: the boys and the girls huddled on opposite sides of the table, their posture and position clearly signifying two separate camps. One of the chief reasons that girls and boys develop different 
styles of talk is that the all-girl and all- boy groups to which they belong interact in vastly different ways. Boys play in larger, more hierarchical groups, while girls play in small groups, often in pairs. Boys' friendship tends to be based on joint activity, while girls' friendship is based on talk. According to Maltz and Borker [18], girls learn to do three things with words: to create and maintain relationships of closeness and equality, to criticize others in acceptable ways and to interpret accurately the speech of other girls, however, boys learn to use words to assert a position of dominance, to attract and maintain an audience and to assert themselves when another speaker has the floor.

The girls' world and the boys' world are embedded in the larger world in society, which is essentially male dominated. Males are expected to possess initiative and demonstrate competence and dominance, females are supposed to display supportiveness, obedience and collaboration. As Tannen observed, for most women, the language of conversation is primarily a language of rapport: a way of establishing connections and negotiating relationships. Emphasis is placed on displaying similarities and matching experiences. [16] From childhood, girls criticize peers who try to stand out or appear better than others. On the other hand, for most men, talk is primarily a means to preserve independence and negotiate and maintain status in a hierarchical social order. This is done by exhibiting knowledge and skill, and by holding center state through verbal performance such as story-telling, joking, or imparting information. From childhood, men learn to use talking as a way to get and keep attention. So they are more comfortable speaking in public.

In China, people have been long influenced by Confucianism which advocated that women's prescribed life status was to serve men, and women were demanded to abide by the ethical code of San cong Si de (three obediences and four virtues).The three obediences are: obedience to father before marriage, to husband after marriage, and to son after husband's death, and four verdures are: morality, proper speech, modest manner and diligent work. This ethical code indeed manifests prejudice against women in ancient China. In general, females behave more sensitive to politeness and use more politeness strategies than male do because of the different subcultures in which they are socialized and genderappropriately are produce and reinforced through the process of socialization.

\section{Conclusion}

As for gender differences in the use of disagreement strategies in overall situations, the present study indicates that both males and females use more mitigated strategies than aggravated strategies when show their disagreement towards others. Females are observed to use more mitigated strategies and less aggravated strategies than males. In examining gender differences in the choice of semantic formulae of mitigated and aggravated strategies, females in the present study tend to choose more Expression of Gratitude plus Avoiding than males, and males tend to choose more Direct Disagreement, Judgmental Vocabulary and Rhetorical Question than females.. Qualitatively speaking, the causes of gender differences in the realization of disagreement strategies are explored from the psychological and socio-cultural perspectives.

\section{References}

[1] Lokoff,Robin, language and women's place, New York: Harper and Row, 1975.

[2] Searle, J. What is a speech act? In Steven, D. (ed.) A Reader. New York: Oxford University Press, 1965.

[3] Holmes, J. Paying compliments: a sex-preferential positive politeness strategy. Journal of Pragmatics. 30:3-15, 1988.

[4] Blum-Kulka, S. \& Olshtain, E. Requests and apologies: A cross-cultural study of speech act realization patterns (CCSARP). Applied linguistics 5-3: 196-213, 1984.

[5] Coates, J. Women, men and Language: A Sociolinguistic Account of Gender Differences in Language. London: Longman,1993.

[6] Miller, R. Power, severity and context in disagreement. Journal of Pragmatics. 32:1087 -1111, 2000.

[7] Muntigl, P. and Turnbull, W. "Conversational structure and facework in arguing". Journal of Pragmatics. Vol.29, 1998, pp. 225-256.

[8] Wang, W. M. A study on politeness strategies of disagreement in Chinese. Unpublished MA thesis, Shandong University, 2006.

[9] Liu, S. Pragmatic strategies and power relations in disagreement. Unpublished PhD thesis, Arizona University, 2004.

[10] Liang, G. D. "A contrastive study on disagreement strategies between American English and Mandarin Chinese". Electronic Resources in Southwest Jiaotong University library, 2003.

[11] Brown, P. and Levinson, S. Universals in language usage: politeness phenomena. In Goody, E. (ed). Questions and Politeness: Strategies in Social Interaction (PP. 56-311). Cambridge: Cambridge University Press, 2000.

[12] Edstrom, A. Expression of disagreement by Venezuelans in conversation: reconsidering the influence of culture. Journal of Pragmatics. 36:1499-1518, 2004.

[13] Liu, P. A pragmatic approach to Chinese EFL learners' realization patterns of disagreement in English. Unpublished MA thesis, Guangdong University of Foreign Studies, 2006.

[14] Zimmerman, D. H. \& West, C. Sex roles, interruptions, and silences in conversation. In Thorne, B. et al. (ed.) Language and sex: differences dominance. Rowley, Newbury House, 1975.

[15] Kalcik, S. Like Ann's Gynecologist or the time I was almost raped. Journal of American Folklore. 88:3-11, 1975.

[16] Tannen, D. Talking from 9 to 5. Women and Men in the Workplace: Language, Sex and Power. New York: Avon Books, 1990.

[17] Edelsky, C. Who's got the floor? Language in Society. 10:383-421., 1980.

[18] Malttz, D. N. \& Borker, R. A. A cultural approach to male and female miscommunication. In Gumperz, J. (ed.) Language and Social Identity. CUP, 1982. 